\title{
ANALISIS SWOT SEBAGAI UPAYA PENGEMBANGAN DAN PENGUATAN STRATEGI BISNIS ( STUDY KASUS PADA UD. GUDANG BUDI, KEC. LAMONGAN)
}

\author{
Danu Kusbandono \\ Prodi Manajemen, Fakultas Ekonomi, Universitas Islam Lamongan \\ $\mathrm{Jl}$. Veteran No.53A Lamongan \\ Telp. ( 0322 ) 324706, Faks. ( 0322 ) 324706 \\ danukusbandono@unisla.ac.id
}

\begin{abstract}
Abstrak
UD. Gudang Budi merupakan unit bisnis yang bergerak dibidang percetakan yang bertempat di area kecamatan dalam kota Lamongan dimana system kerjanya melakukan FIFO( First in First Out) dan juga realtime pembuatan desain dimana konsumen bisa langsung mengawasi pembuatan desain yang di inginkan. Dalam pelaksanaan strateginya UD. Gudang Budi bisa dikatakan belum membuahkan hasil yang maksimal dikarenakan belum memiliki backup alat cetak sehingga order dari konsumen yang masuk dalam antrian semakin menumpuk dan juga cabang baru untuk memposisikan diri sebagai puncak kepemimpinan. Dengan adanya permasalahan dalam UD. Gudang Budi, maka penelitian berinisiatif ini menggunakan analisis SWOT sebagai teknik dasar untuk melihat faktor internal dan eksternal yang mempunyai tujuan untuk menentukan strategi pemasaran, sehingga diharapkan memperoleh keuntungan yang maksimal. Hasil penelitian ini menyimpulkan bahwa strategi yang bisa digunakan UD. Gudang Budi adalah strategi agresif yakni dengan menambah unit alat cetak sehingga berpengaruh menurunkan antrian permintaan desain grafis konsumen, menambah pendingin ruangan pada area operator desain grafis supaya konsumen merasa nyaman, mendirikan cabang baru di area dengan populasi tinggi dimana ada banyak sekali instansi yang berdiri.
\end{abstract}

Kata kunci: Analisis SWOT, EFAS, IFAS, Strategi Pemasan.

\section{PENDAHULUAN}

Perkembangan teknologi yang terstruktur, masif dan cepat berubah merupakan hal yang tidak asing lagi bagi perusahaan, khususnya perusahaan yang menggunakan media cetak dalam menjalankan bisnisnya, semisal perusahaan percetakan, sehingga perusahaan tersebut berlomba-lomba dalam hal pemasaran untuk dapat memikat konsumen melalui media elektronik dan media cetak, ketatnya persaingan bisnis secara tidak langsung mempengaruhi laba perusahaan, dan berdampak pada perkembangan perusahaan tersebut, sehingga memicu perusahaan untuk meningkatkan kuantitas serta kualitas dari promosi dan juga pelayanan .

UD. Gudang Budi merupakan perusahaan bisnis skala kecil yang bergerak di bidang percetakan, dimana sudah berdiri sejak lama di daerah jantung kota Lamongan Provinsi Jawa 
Timur, yang di awali dengan bisnis jasa fotokopi dan kemudian beralih menjadi jasa percetakan, dengan seiring perkembangan jaman yang kian lama semakin berkembang dalam hal teknologi, semisal software desain grafis mau tidak mau pengelola bisnis percetakan memilah-milah software yang mempunyai kualitas hasil yang baik, user friendly serta bisa memangkas waktu.

Seiring berjalannya waktu dan bertambahnya bisnis percetakan, maka strategic plan merupakan kunci sukses dalam berbisnis sehingga secara tidak langgsung menjadikan persaingan semakin ketat dan berfluktuasi secara tidak pasti, dalam prakteknya UD. Gudang Budi selalu menerima pesanan yang di minta oleh masyarakat tanpa sedikitpun menolak, sehingga konsumen merasa senang, Sistem pemasaran yang diterapkan menggunakan media cetak yaitu antara lain: banner \& pamflet, selain itu juga menggunakan media promosi di radio lokal. Selama ini dalam prakteknya menitik beratkan order konsumen secara langsung yaitu, konsumen sendiri datang langsung untuk memesan desain, sehingga dirasa belum cukup dalam segi pemasaran.

\section{KAJIAN PUSTAKA}

Menurut Agustina Shinta (2011:84), Jasa adalah setiap tindakan atau kegiatan yang dapat ditawarkan oleh satu pihak kepada pihak lain, yang pada dasarnya tidak berwujud dan tidak mengakibatkan kepemilikan apapun. Produksinya dapat dikaitkan pada suatu produk fisik.

Menurut Agustina Shinta (2011:2), Pemasaran adalah suatu proses dan manajerial yang membuat individu atau kelompok mendapatkan apa yang mereka butuhkan dan inginkan dengan menciptakan, menawarkan dan mempertukarkan produk yang bernilai kepada pihak lain atau segala kegiatan yang menyangkut penyampaian produk atau jasa mulai dari produsen sampai konsumen.

Dari pengertian di atas, Pemasaran merupakan devisi yang krusial dari suatu bisnis, dimana lingkup operasionalnya sangat luas. Dalam kenyataanya pemasar memerlukan koordinasi yang efektif dan efisien, sehingga memerlukan manajemen yang memadai.

Menurut Agustina Shinta (2011:2), Manajemen pemasaran adalah suatu usaha untuk merencanakan, mengimplementasikan (yang terdiri dari kegiatan mengorganisaikan, 
mengarahkan, mengkoordinir) serta mengawasi atau mengendalikan kegiatan pemasaran dalam suatu organisasi agar tercapai tujuan organisasi secara efesien dan efektif. Di dalam fungsi manajemen pemasaran ada kegiatan menganalisis yaitu analisis yang dilakukan untuk mengetahui pasar dan lingkungan pemasarannya, sehingga dapat diperoleh seberapa besar peluang untuk merebut pasar dan seberapa besar ancaman yang harus dihadapi. Fungsi Manajemen Pemasaran (Kotler, 2000)

Menurut Pardede (2011:23), manajemen strategi dapat diartikan sebagai penentuan serangkaian keputusan dan tindakan yang menyangkut arah perjalanan perusahaan di masa depan, penyelarasan sasaran setiap bagian perusahaan, pengelolaan sumberdaya sesuai dengan lingkungannya, serta pembuatan siasat yang benar, yang dimaksud untuk pencapaian sasaransasaran.

Richard L. Daft (2010:249) mendefinisikan strategi (strategy) secara eksplisit, yaitu rencana tindakan yang menerangkan tentang alokasi sumber daya serta berbagai aktivitas untuk menghadapi lingkungan, memperoleh keunggulan bersaing, dan mencapai tujuan perusahaan. Keunggulan bersaing (competitive advantage) adalah hal yang membedakan suatu perusahaan dari perushaan lain dan member ciri khas bagi perusahaan untuk memenuhi kebutuhan pasar konsumen. Inti perumusan strategi adalah menentukan bagaimana perusahaan kita akan berbeda dengan perusahaan lain.

Dalam upaya untuk menentukan strategi, maka diperlukan analisis dasar yang berkaitan dengan faktor internal dan eksternal, yaitu: menggunakan analisis SWOT (Strenghts, Weaknesses, Opportunities, Threats) Menurut Rangkuti (2015:19), Analisis SWOT (Strenghts,

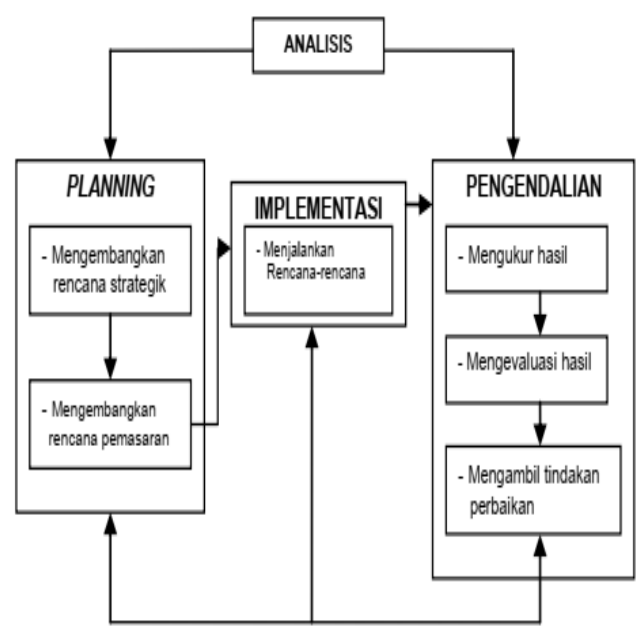

Weaknesses, Opportunities, Threats) merupakan salah satu alat bantu yang dapat digunakan untuk 
mengembangkan strategi yang berlandaskan pada situasi di sekeliling perusahaan yang mempengaruhi kinerja perusahaan. Faktor ini diklasifikasikan sebagai faktor internal dan eksternal perusahaan yaitu hubungan antara organisasi dan masyarakat yang menciptakan dan mendukungnya. Di dalam masyarakat terdapat faktor berpengaruh organisasi.

\section{Analisis SWOT}

a) Matriks Srategi IFAS \& EFAS

Penentuan nilai faktor dalam pembuatan matriks SWOT terdiri dari,faktor internal dan eksternal. Masing-masing kriteria dibuatkan kolom agar bisa memilah-milah kriteria , kemudian tiap kriteria diberikan bobot mulai dari 0,0 (tidak penting) sampai dengan 1,0 (sangat penting), setiap poin kriteria bisa memberikan efek yang signifikan terhadap strategi yang akan di gunakan.selanjutnya menghitung total rating tiap-tiap kriteria sehingga didapat skala, yang dimulai dari 1 (poor) sampai dengan 4 (outstanding). Nilai rating berdasar pada kenyataan dilapangan yang bisa mempengaruhi kondisi perusahaan, pemberian rating dari faktor peluang bersifat positif (nilai peluang kecil diberi rating +1 dan nilai peluang besar diberi rating 4), begitu juga sebaliknya apabila nilai ancaman semakin kecil maka diberi rating 4 dan nilai ancaman semakin besar diberi nilai 1), Selanjutnya mengkalikan nilai bobot dengan rating agar didapat nilai skor yang akan disusun pada kolom ke-4, jumlahkan skor pembobotan (pada kolom 4), untuk memperoleh total skor pembobotan, fungsi dari hasil skor bagi perusahaan yang adalah untuk menentukan strategi yang akan dikembangkan kedepan guna mendapatkan hasil yang optimal.

\section{Analisis SWOT: Teknik} Membedah Kasus Bisnis, 18th ed. (Gramedia Pustaka Utama, 2014.)

Tabel 1. Tabel Perhitungan Faktor Eksternal [Freddy Rangkuti,

\begin{tabular}{|l|l|l|l|}
\hline Faktor-faktor & Bobot & Rating & Skor \\
Strategi Eksternal & & & \\
\hline PELUANG : & & & \\
Peluang 1 & & & \\
Peluang 2 & & & \\
Peluang 3 & & \\
Peluang 4 & & & \\
Peluang 5 & & & \\
\hline ANCAMAN : & & & \\
Ancaman 1 & & & \\
Ancaman 2 & & & \\
Ancaman 3 & & & \\
Ancaman 4 & & & \\
Ancaman 5 & & & \\
\hline TOTAL & 1 & & \\
\hline
\end{tabular}


Tabel 2: Tabel Perhitungan Faktor Internal

\begin{tabular}{|c|l|l|l|}
\hline Faktor-faktor & Bobot & Rating & Skor \\
Strategi Internal & & & \\
\hline KEKUATAN : & & & \\
Kekuatan 1 & & & \\
Kekuatan 2 & & & \\
Kekuatan 3 & & & \\
Kekuatan 4 & & & \\
Kekuatan 5 & & & \\
\hline KELEMAHAN : & & & \\
Kelemahan 1 & & & \\
Kelemahan 2 & & & \\
Kelemahan 3 & & & \\
Kelemahan 4 & & & \\
Kelemahan 5 & & & \\
\hline TOTAL & 1 & & \\
\hline
\end{tabular}

Setelah mendapatkan hasil perhitungan nilai factor dari IFAS dan EFAS, langkah selanjutnya membuat diagram cartesius perusahaan guna memposisikan letak kondisi perusahaan saat ini. Kemudian merumuskan strategi alternatif yang tepat dan efisien.

\section{METODE PENELITIAN}

\section{Metode Pengumpulan Data}

Menurut Sugiyono (2013:224) teknik pengumpulan data merupakan langkah yang paling strategis dalam penelitian, karena tujuan utama dari penelitian adalah mendapatkan data.

\section{A. Teknik Wawancara,}

Menurut Esterberg dalam Sugiyono (2013:231) wawancara merupakan pertemuan dua orang untuk bertukar informasi dan ide melalui tanya jawab, sehingga dapat dikontruksikan makna dalam suatu topik tertentu.

B. Teknik Pengamatan/Observasi, Sutrisno Hadi dalam Sugiyono (2013:145) mengemukakan bahwa, observasi merupakan suatu proses yang kompleks, suatu proses yang tersusun dari berbagai proses biologis dan psikhologis. Dua di antara yang terpenting adalah proses-proses pengamatan dan ingatan.

\section{c. Teknik Dokumentasi,}

Menurut Sugiyono (2013:240) dokumen merupakan catatan peristiwa yang sudah berlalu. Dokumen bisa berbentuk tulisan, gambar, atau karya-karya monumental dari seorang. Dokumen yang berbentuk tulisan misalnya catatan harian, sejarah kehidupan (life histories), ceritera, biografi, peraturan, kebijakan. Dokumen yang berbentuk gambar misalnya foto, gambar hidup, sketsa dan lainlain. Dokumen yang berbentuk karya misalnya karya seni, yang dapat berupa gambar, patung, film dan lain-lain. Studi dokumen merupakan pelengkap dari penggunaan metode observasi dan 
wawancara dalam penelitian

kualitatif.

\section{Metode Analisis Data}

Proses penyusunan dalam merencanakan strategi didapat melalui tiga tahap analisis, yaitu:

a. Tahap pengumpulan data (informasi faktor eksternal dan internal)

b. Tahap analisis (matriks internal eksternal, diagram cartesius, matriks SWOT)

c. Tahap pengambilan keputusan

Tahap pengumpulan data merupakan kegiatan pengumpulan data sekaligus klarifisifikasian atas kejadiankejadian yang di teliti

Tahap analisis merupakan tahap setelah terkumpulnya data penunjang,setelah semua informasi sudah di kumpulkan maka dapat dilanjutkan memasukkan semua informasi ke dalam analisis SWOT. Setelah data dianalisis maka barulah bisa diambil beberapa keputusan yang sesuai kondisi perusahaan.

Menurut Rangkuti (2014) berdasarkan matriks SWOT terdapat empat kuadran berbeda, yaitu:

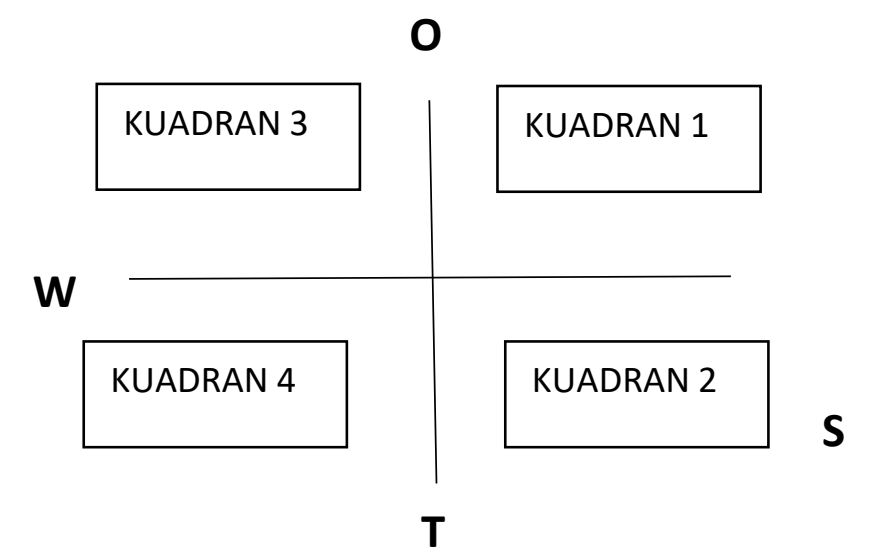

Gambar 1. Matrik SWOT

a. Menurut Raangkuti (2014), strategis pertimbangan dari kombinasi empat faktor yaitu:

1) Strategi SO

Strategi ini dibuat berdasarkan jalan pemikiran perusahaan, yaitu dengan menggunakan seluruh kekuatan untuk memanfaatkan peluang.

2) Strategi ST

Ini adalah strategi untuk menggunakan kekuatan yang dimiliki perusahaan dengan cara menghindari ancaman.

3) Strategi WO

Strategi ini diterapkan berdasarkan pemanfaatan peluang yang ada, dengan cara mengatasi kelemahankelemahan yang dimiliki.

4) Strategi WT

Strategi ini didasarkan pada kegiatan yang bersifat defensive dan ditujukan untuk 


\author{
meminimalkan kelemahan \\ yang ada serta menghindari \\ ancaman.
}

Setelah melakukan perhitungan matrik IFAS dan EFAS maka dapat dihasilkan informasi tingkat internal dan eksternal perusahaan. Berdasarkan perhitungan tersebut hasilnya akan di implementasikan dalam Diagram Cartesius SWOT.

Tabel 3, Matrik Faktor Strategi Internal

\begin{tabular}{|c|c|c|c|}
\hline $\begin{array}{l}\text { Faktor } \\
\text { strategi } \\
\text { Internal }\end{array}$ & Bobot & Rating & $\begin{array}{l}\text { Bobot X } \\
\text { Rating }\end{array}$ \\
\hline uatan(Stre nghts) & $\mathbf{X}$ & $\mathrm{X}$ & $\mathbf{X}$ \\
\hline Jumlah & $\mathrm{X}$ & $x$ & $\mathrm{X}$ \\
\hline $\begin{array}{l}\text { Kelemahan } \\
\text { (Weaknes) }\end{array}$ & $\mathrm{X}$ & $\mathrm{x}$ & $\mathbf{X}$ \\
\hline Jumlah & $\mathbf{x}$ & $\mathbf{x}$ & $\mathbf{X}$ \\
\hline Total & $\mathbf{x}$ & $\mathbf{x}$ & $\mathbf{x}$ \\
\hline
\end{tabular}

\section{HASIL DAN PEMBAHASAN}

Pemaparan hasil identifikasi terhadap faktor lingkungan internal dan eksternal UD. Gudang Budi Lamongan, maka dapat disimpulkan kategori yang menjadi faktor internal dan eksternal antara lain:

1. Faktor Internal (IFAS)

a. Kekuatan (Strenghts)

1) Mempunyai berbagai macam jenis produk (sehingga konsumen tidak perlu repot-repot mencari produk dalam kategori yang sejenis).

2) Sistem komunikasi pelanggan yang digunakan UD. Gudang Budi yang menggunakan aplikasi Whatsapp, (sehingga konsumen bisa memantau langsung proses editing pesanan)

3) UD. Gudang Budi menggunakan jaringan internal $L A N$ (untuk komunikasi antar komputer desain grafis ,4 unit komputer Desain grafis)

4) UD. Gudang Budi menggunakan system FIFO ( First In First Out), dimana konsumen yang datang lebih awal maka akan langsung di layani sampai konsumen merasa puas dengan hasil desain.

5) Pelayanan yang optimal dan ramah (dalam segala kebutuhan produk khususnya operator desain dan kasir).

6) Tempat yang strategis di pusat kota (dimana banyak sekali berbagai instansi 
bisa cepat mengakses ataupun datang langsung).

7) UD. Gudang Budi menjadi sarana siswa atau mahasiswa yang melaksanakan program praktek kerja lapangan (PKL), (secara tidak langsung wali murid atau wali mahasiswa mengetahui eksistensi jasa percetakan UD. Gudang Budi, sehingga sangat membantu proses pemasaran).

b. Kelemahan (Weaknesses)

1) Sering terjadi overload demand (beberapa pesanan tidak dapat terselesaikan tepat waktu).

2) Kurangnya tenaga operator desain grafis (berdampak pada overload demand dan keterlambatan proses cetak).

3) Mesin cetak yang masih berjumlah satu unit (proses cetak dalam antrian dan memakan waktu).

4) Maintenance peralatan cetak yang tidak terjadwal (menhambat proses cetak jika terjadi kerusakan).

5) Kantor kerja operator belum terpasang $\mathrm{AC}$ (sehingga masih terasa panas, hanya ruang mesin cetak saja yang terpasang AC untuk menjaga suhu mesin cetak supaya optimal dalam pengoperasiannya).

6) Belum memiliki cabang ( di kecamatan dengan padat penduduk).

2. Faktor Strategis Eksternal (EFAS)

a.Peluang (Opportunities)

1) Mempunyai pelanggan tetap (dalam hal pemesanan percetakan).

2) Walaupun teknologi informasi semakin berkembang, pangsa pasar usaha jasa percetakan sangatlah luas dan masih banyak di butuhkan masyarakat.

3) Kualitas mesin cetak yang bagus dan mudah (perawatannya).

4) Bertambahnya industri di lingkungan lokal (tiap tahun yang bertambah 
banyak minat pada kebutuhan percetakan).

5) Event (Pengadaan acara tiap instansi)

6) Mempunyai jaringan pemasaran internal yang luas.

b. Ancaman (Threats)

1) Bertambahnya jumlah pesaing.

2) Harga (harga produk pesaing yang tidak bisa dipastikan).

3) Kenaikan harga bahan baku (tidak pasti).

4) Tidak adanya kebijakan daerah mengenai pembatasan pebisnis jasa percetakan.

5) Kepekaan harga oleh konsumen yang bisa membuat konsumen berpindah ke pesaing.

6) Jumlah unit peralatan atau anak cabang perusahaan pesaing yang dapat memangkas waktu cetak dan mendapatkan konsumen
Tabel 5

Matrik Faktor Strategi Internal (IFAS).

\begin{tabular}{|c|c|c|c|}
\hline strategi & $\begin{array}{l}\text { Bob } \\
\text { ot }\end{array}$ & Rati & $\begin{array}{l}\text { Bobo } \\
\text { t X } \\
\text { Ratin } \\
\text { g }\end{array}$ \\
\hline \multicolumn{4}{|l|}{ Kekuatan (Strenght) } \\
\hline $\begin{array}{l}\text { Mempunyai berbagai macam } \\
\text { jenis produk }\end{array}$ & 0,1 & 2 &, 2 \\
\hline $\begin{array}{l}\text { Sistem komunikasi pelanggan } \\
\text { yang digunakan UD. Gudang } \\
\text { Budi yang menggunakan } \\
\text { aplikasi Whatsapp }\end{array}$ & 0,2 & 4 &, 8 \\
\hline $\begin{array}{l}\text { menggunakan } \\
\text { internal } L A N \quad \text { jaringan } \\
\text { computer operator desai) }\end{array}$ & 0,1 & 3 &, 3 \\
\hline menggunakan system FIFO & 0,1 & 4 &, 4 \\
\hline $\begin{array}{l}\text { Pelayanan yang optimal dan } \\
\text { ramah }\end{array}$ & 0,2 & 4 &, 8 \\
\hline $\begin{array}{l}\text { Tempat yang strategis di } \\
\text { pusat kota }\end{array}$ & $\mathrm{i} 0,2$ & 4 &, 8 \\
\hline Tempat PKL & 0,1 & 2 &, 2 \\
\hline Total & 1 & &, 5 \\
\hline Kelemahan (weaknesess) & $\begin{array}{l}\text { Bob } \\
\text { ot }\end{array}$ & \begin{tabular}{|l|} 
Rati \\
ng \\
\end{tabular} & \begin{tabular}{|l|} 
Bo \\
bot \\
X \\
Rati \\
ng \\
\end{tabular} \\
\hline $\begin{array}{l}\text { Sering terjadi overload } \\
\text { demand }\end{array}$ & 0,24 & 2 &, 48 \\
\hline $\begin{array}{l}\text { Kurangnya tenaga operator } \\
\text { desain grafis }\end{array}$ & 0,01 & 2 &, 02 \\
\hline $\begin{array}{l}\text { Mesin cetak yang masih } \\
\text { berjumlah satu unit }\end{array}$ & 0,12 & 3 &, 36 \\
\hline $\begin{array}{l}\text { Maintenance peralatan cetak } \\
\text { yang tidak terjadwal }\end{array}$ & 0,03 & 2 &, 06 \\
\hline $\begin{array}{l}\text { Kantor kerja operator belum } \\
\text { terpasang AC }\end{array}$ & 0,1 & 2 &, 2 \\
\hline Belum memiliki cabang & 0,5 & 3 &, 5 \\
\hline Total & 1 & &, 12 \\
\hline
\end{tabular}


Tabel 6 Matrik Faktor Strategi

Eksternal (EFAS)

\begin{tabular}{|c|c|c|c|}
\hline $\begin{array}{l}\text { Faktor } \\
\text { strategi } \\
\text { Eksternal }\end{array}$ & $\begin{array}{l}\text { Bobo } \\
\mathbf{t}\end{array}$ & $\begin{array}{l}\text { Rati } \\
\text { ng }\end{array}$ & \begin{tabular}{|l} 
Bob \\
ot \\
X \\
Ratin \\
g
\end{tabular} \\
\hline \multicolumn{4}{|l|}{$\begin{array}{l}\text { Peluang } \\
\text { (Opportunities) }\end{array}$} \\
\hline $\begin{array}{l}\text { Mempunyai } \\
\text { pelanggan tetap }\end{array}$ & 0,2 & 3 & 0,6 \\
\hline $\begin{array}{l}\text { teknologi } \\
\text { informasi semakin } \\
\text { berkembang }\end{array}$ & 0,1 & 2 & 0,2 \\
\hline $\begin{array}{ll}\text { Kualitas mesin } \\
\text { cetak yang bagus } \\
\text { dan mudah }\end{array}$ & 0,2 & 3 & 0,6 \\
\hline $\begin{array}{l}\text { Bertambahnya } \\
\text { industri di } \\
\text { lingkungan lokal }\end{array}$ & $\begin{array}{l}0,2 \\
3\end{array}$ & 4 & 0,92 \\
\hline $\begin{array}{l}\text { Event (Pengadaan } \\
\text { acara tiap instansi) }\end{array}$ & $\begin{array}{l}0,1 \\
5\end{array}$ & 3 & 0,45 \\
\hline $\begin{array}{l}\text { Mempunyai } \\
\text { jaringan } \\
\text { pemasaran internal } \\
\text { yang luas }\end{array}$ & $\begin{array}{l}0,1 \\
2\end{array}$ & 4 & 0,48 \\
\hline Total & 1 & & 3,25 \\
\hline $\begin{array}{l}\text { Ancaman } \\
\text { (Threats) }\end{array}$ & $\begin{array}{l}\text { Bob } \\
\text { ot }\end{array}$ & $\begin{array}{l}\text { Rati } \\
\text { ng }\end{array}$ & $\begin{array}{l}\text { Bobot } \\
\text { X } \\
\text { Rating }\end{array}$ \\
\hline $\begin{array}{l}\text { Bertambahnya } \\
\text { jumlah pesaing }\end{array}$ & $\begin{array}{l}0,1 \\
5\end{array}$ & 3 & 0,45 \\
\hline Harga & $\begin{array}{l}0,2 \\
5\end{array}$ & 3 & 0,75 \\
\hline $\begin{array}{ll}\text { Kenaikan } & \text { harga } \\
\text { bahan baku } & \end{array}$ & $\begin{array}{l}0,1 \\
5\end{array}$ & 2 & 0,3 \\
\hline $\begin{array}{ll}\text { Tidak } & \text { adanya } \\
\text { kebijakan } & \text { daerah } \\
\text { mengenai } & \\
\text { pembatasan } & \\
\text { pebisnis } & \text { jasa } \\
\text { percetakan } & \end{array}$ & $\begin{array}{l}0,1 \\
7\end{array}$ & 2 & 0,34 \\
\hline $\begin{array}{l}\text { Kepekaan harga } \\
\text { oleh konsumen }\end{array}$ & $\begin{array}{l}0,1 \\
3\end{array}$ & 2 & 0,26 \\
\hline $\begin{array}{l}\text { Jumlah unit } \\
\text { peralatan atau anak } \\
\text { cabang perusahaan }\end{array}$ & $\begin{array}{l}0,1 \\
5\end{array}$ & 2 & 0,3 \\
\hline
\end{tabular}

\begin{tabular}{|l|l|l|l|}
\hline $\begin{array}{l}\text { Faktor } \\
\text { strategi } \\
\text { Eksternal }\end{array}$ & $\begin{array}{l}\text { Bobo } \\
\text { t }\end{array}$ & $\begin{array}{l}\text { Rati } \\
\text { ng }\end{array}$ & $\begin{array}{c}\text { Bob } \\
\text { ot } \\
\text { X } \\
\text { Ratin } \\
\text { g }\end{array}$ \\
\hline pesaing & & & \\
\hline Total & & & \\
\hline
\end{tabular}

Dari hasil matrik SWOT diatas dapat disimpulkan UD. Gudang Budi untuk factor internal berada pada $(1,38)$, dan factor eksternal berada pada $(0,85)$ sebagaimana tampak pada gambar:

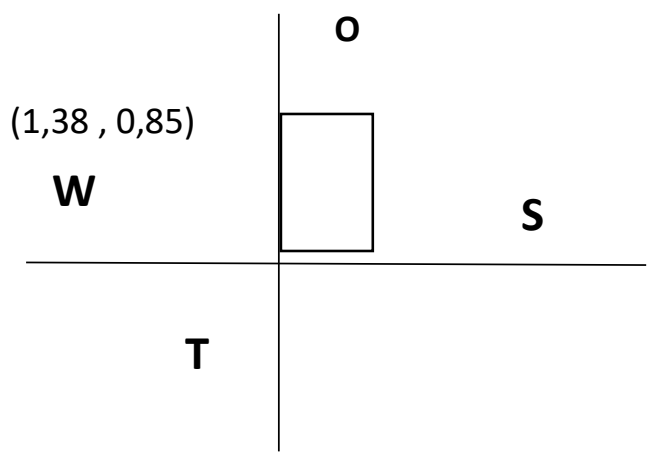

Gambar 2. Diagram Cartecius

Dari gambar matriks SWOT diatas didapat hasil bahwa UD. Gudang Budi berada pada kuadran I, maka strategi yang dapat dilakukan adalah strategi agresif, dimana strategi agresif ini perusahaan dituntut untuk berfokus pada:

1. Peningkatan sumberdaya, bisa berupa penambahan alat cetak dan pendingin ruangan untuk ruang operator desain.

2. Memperluas jaringan, bisa membuat MOU dengan Instansi terutama pihak pengadaan barang. 
3. Pembentukan atau pendirian cabang baru, berlokasi strategis dimana populasi masyarakat bisa di bilang terbanyak selain area kecamatan kota.

\section{KESIMPULAN}

Berdasarkan hasil penelitian yang telah dilakukan terhadap faktor internal dan eksternal dengan menggunakan analisis SWOT dapat disimpulkan bahwa UD. Gudang Budi berada diantara kuadran I (kekuatan dan peluang) sehingga menitik beratkan pada perusahaan untuk menggunakan strategi agresif dimana untuk melakukan pengembangan guna mempertahankan posisi puncak untuk menutup celah.

pada faktor ancaman dan kelemahan dengan cara penambahan unit alat cetak, penambahan pendingin ruangan yang membuat nyaman konsumen saat melihat desain grafis yang dikerjakan dan mendirikan cabang baru untuk menambah penguasaan pangsa pasar dan juga supaya lebih dikenal oleh masyarakat luas.

\section{DAFTAR PUSTAKA}

Rangkuti, Freddy. (2014). Analisis SWOT Teknik Membedah Kasus
Bisnis. Jakarta: Gramedia Pustaka Utama.

Richard L. Daft, 2010, Era Baru Manajemen,Edward Tanujaya, Edisi 9,Salemba Empat

Agustina Shinta, 2011, Manajemen Pemasaran, Edisi 1, UB Press

Pontas Pardede, M. 2011. Manajemen Strategik dan Kebijakan Perusahaan, Jakarta: Mitra Wacana Media

Rangkuti, Freddy. 2015. Analisis SWOT Teknik Membedah Kasus Bisnis. Penerbit PT. GramediaPustakaUtama. Jakarta. Sugiyono.2010. Metode Penelitian Kuantitatif Kualitatif dan $R \& D$. Bandung, Indonesia: Alfabeta.

Sugiyono, 2013, Metode Penelitian Kualitatif dan $R \& D$, Alfabeta, CV.Bandung 
